\title{
Anarchasis Cloots, le Prussien francophile. Un philosophe au service de la Révolution française et universelle
}

\section{Annie Duprat}

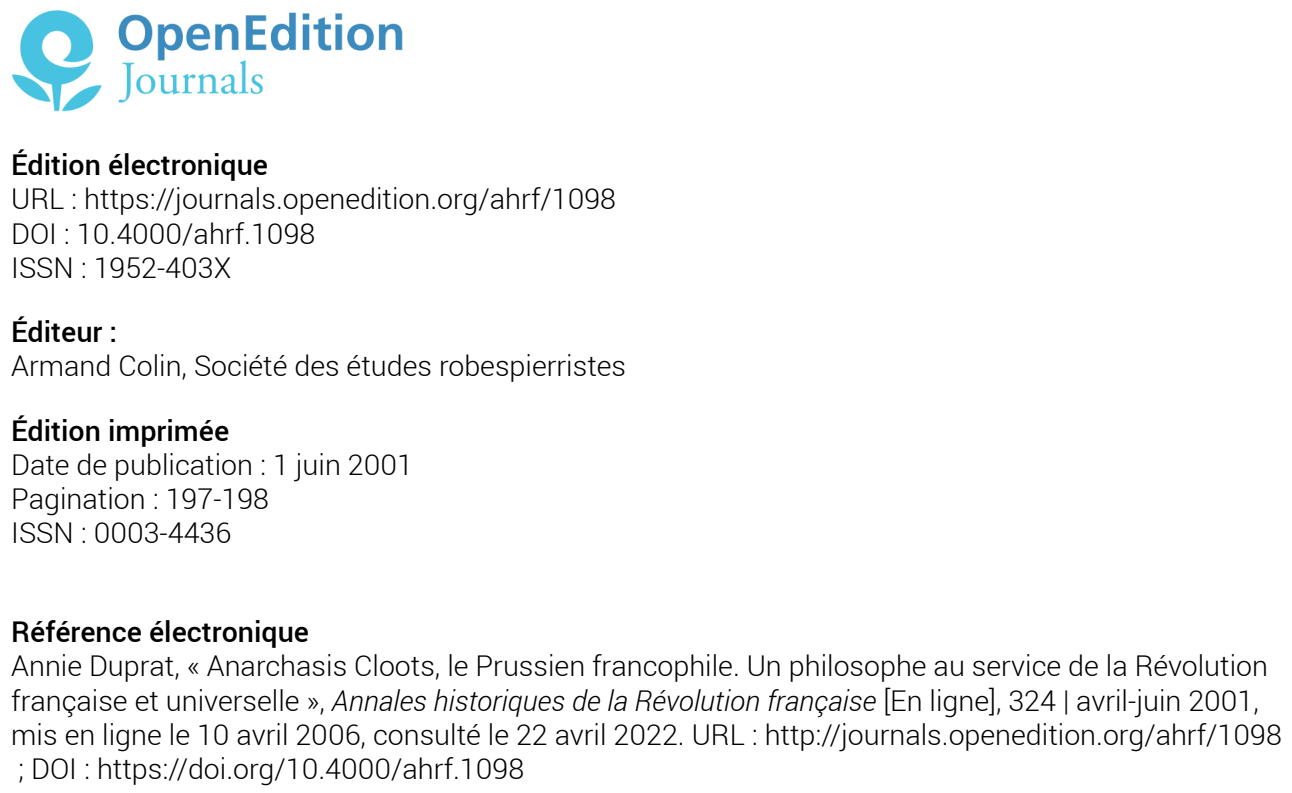

Ce document a été généré automatiquement le 22 avril 2022.

Tous droits réservés 


\title{
Anarchasis Cloots, le Prussien francophile. Un philosophe au service de la Révolution française et universelle
}

\author{
Annie Duprat
}

\section{RÉFÉRENCE}

François Labbé, Anarchasis Cloots, le Prussien francophile. Un philosophe au service de la Révolution française et universelle, Paris, L'Harmattan, coll. l'Allemagne d'hier et d'aujourd'hui, 1999, $546 \mathrm{p}$.

1 Placé sous l'égide d'une citation de Balzac extraite du Curé de Tours, exaltant la grandeur et les dangers du cosmopolitisme, ce gros livre se présente sous la forme d'une biographie très originale, très différente, de l'aveu même de son auteur, de l'ouvrage à présent classique que nous avait donné Roland Mortier en 1995 sous le titre Anarchasis Cloots ou l'Utopie foudroyée. Le livre se présente sous la forme d'un parcours intellectuel de celui qui se qualifiait lui-même «l'orateur du genre humain» et que son nouveau biographe présente comme «un Gaspard Hauser plus que comme un Candide». Né en Prusse le 24 juin 1755 dans une famille de négociants et de financiers d'origine hollandaise, le jeune Jean-Baptiste Cloots a reçu une éducation française. Si l'on ne sait pas grand chose de son enfance, son adolescence passée depuis l'âge de 11 ans à Paris, au collège de Plessis-Sorbonne est marquée par des influences maçonniques éclairées, celles que lui prodigue la famille des Vandenyver, membres de la loge des Amis réunis. Il est particulièrement séduit par les cours de son professeur de philosophie, Sulzer, humaniste optimiste, qui croit à la bonté et à la perfectibilité du genre humain; il fera sienne toute sa vie une des maximes fondatrices de ces années de formation, «la voie d'autorité est une voie de perdition» (p. 47). Si, dès 1770, il doit rejoindre une école militaire, il la quitte en mai 1773. Mais quel était son sentiment 
alors? Dans des écrits très postérieurs, il porte des jugements très durs sur le militarisme prussien, accusé d'être une entreprise de déshumanisation. Au cours des années suivantes, il effectue de très nombreux séjours à Paris, où il a des attaches familiales et un grand réseau de relations; il est convaincu de l'excellence et de l'universalité de la culture et de la langue françaises, enthousiasme qu'il fait partager aux Prussiens, ce qui justifie le sous-titre de cet ouvrage, «le Prussien francophile». La suite est connue. Très actif au cours des journées d'octobre 1789, il fréquente autant les Jacobins que plus tard les Cordeliers, mais il ne signe pas la pétition du Champ-de-Mars; élu député par le département de l'Oise à la Convention nationale, mais toujours étranger, il appelle de ses vœux une République universelle du genre humain puis, en 1793, défend le projet d'une République fédérative des individus, ce qui le place à l'écart, tant des Montagnards que des Girondins. Dénoncé par Robespierre comme un phraseur exalté et encombrant, ce dont témoigne la somme des lettres et des écrits recueillis et remarquablement étudiés par François Labbé, il est exclu de la Convention en décembre 1793. Le chapitre qui décrit «la fin des illusions» (pp. 394-425) montre en réalité la fin des illusions de celui qui avait choisi le patronage d'Anarchasis, ce philosophe scythe de l'époque archaïque paré des vertus de l'homme pur et sans tache, ami de Solon. Mais l'auteur, passionné par son sujet est également aveuglé par ses sympathies au point d'écrire péremptoirement: «la chute des Girondins et la relance de la campagne de déchristianisation alors que l'imprécateur [souligné dans le texte] Robespierre occupe une position de force au sein du Comité de sûreté générale depuis son élection du 27 juillet 1793 et que la France bascule dans la dictature», ce qui clôt sans l'avoir ouvert tout débat sur la nature de la Terreur. Cependant, le livre fourmille d'informations nouvelles et, pour la plupart, inédites, puisque l'enquête de Francois Labbé l'a conduit à étudier des fonds manuscrits en France, en Allemagne et aux PaysBas, et à collationner un nombre impressionnant d'écrits imprimés, de Cloots comme de ses contemporains.

2 Très agréable à lire grâce à un style nerveux et précis, cet ouvrage est d'une grande richesse documentaire. Si Anarchasis Cloots n'a pas fait preuve d'une très grande efficacité politicienne, c'est sans doute en raison de sa fougue et de son impatience à voir se régénérer le monde qu'il croyait enfin délivré par le souffle de la Révolution. Les deux derniers chapitres, consacrés au «mythe de Cloots» (pp. 427-490) et à sa postérité «influences» (pp. 491-509) expliquent en partie la puissance de l'imaginaire révolutionnaire romantique dans la France du xixe siècle, et bien au-delà, on pense bien sûr aux mouvements tiers-mondistes du xx ${ }^{e}$ siècle et à Frantz Fanon. 